\title{
Mohit Bhandari, Anders Joensson, Prolog: Einhorn, Thomas A.: Getting your research paper published: a surgical perspective
}

\author{
Thieme Verlag, New York, Stuttgart, 2010, 180 pp, 30 figs., Softcover, EUR (D) 69, \\ 95 CHF 116,00, ISBN: 978-3-13-149991-2
}

Pierre Kehr

Received: 24 November 2011 / Accepted: 26 November 2011/Published online: 7 December 2011

(C) Springer-Verlag 2011

Let us be perfectly clear: why anyone wishing to have his work published should read this book?

Because this synthetic book makes it possible to know all the specificities and the traps of publications in English language (especially when the author is not a native speaker) in order to avoid corrections on the form. Because this handy guide provides advice on the presentation of a scientific article as well as on oral communications and posters which often have to be written at the same time. Because the important sections of an article are detailed, with examples of tips to follow and errors to be avoided.

Certain chapters are of more general interest such as: Why should we publish papers? Common pitfalls in the reporting of surgical results; when do you need a statistician?

The other chapters are directly related to drafting, from the abstract to the conclusion, while reviewing the choices available to the authors, with the dos and don'ts of writing.

After having read but mostly used this guide, you will be able to put in practice all you have learned from this book when working on articles.

Alain Graftiaux

Strasbourg

Conflict of interest None.

This book review was previously published in Argo Spine News and Journal (2011) 23:174. doi:10.1007/s12240-011-0032-8.

P. Kehr $(\bowtie)$

Strasbourg, France

e-mail: kehrpier@aol.com 